\title{
ESTRATEGIAS DE COMUNICACIÓN INSTITUCIONAL EN LA INFORMACIÓN TELEVISIVA
}

\section{STRATEGIES OF INSTITUTIONAL COMMUNICATION IN TELEVISION INFORMATION}

\author{
José Antonio Navarro Moreno \\ (Universidad Sevilla) \\ janava@us.es \\ Agustín Olmo López \\ (Universidad Sevilla) \\ aolmo@us.es
}

Resumen: El Departamento de comunicación institucional de la Unión Europea (UE) es uno de los mas grandes del mundo. Produce actividad informativa de la Comisión Europea, el Parlamento, y el Fondo Regional. En los últimos años, algunos acontecimientos han deteriorado la imagen de la opinión pública sobre EU (euro, ampliación, constitución, crisis). Este artículo estudia las intenciones y estrategias informativas de la UE en grandes campañas de comunicación a diferentes niveles: continental, nacional o regional. Analizamos cuál es la relación directa entre ese propósito y el resultado en forma de la información que emiten los medios. El periodo de estudio es el año 2013 y las fuentes utilizadas son la documentación enviada por la UE a periodistas y las emisiones de noticias en grandes medios andaluces. La discusión trata sobre la distancia entre las la UE y los medios; los comunicados de la UE el estilo deshumanizado; la falta de correlación entre información recibida de la UE e información emitida por los medios; así como la preferencia por emitir noticias de la EU sobre cuestiones económicas y de infraestructuras; y que la identidad visual mas frecuente de la UE son sus edificios.

Palabras clave: Unión Europea, Comunicación institucional, Televisión, Relaciones Públicas, Información, noticias, Andalucia, campañas mediáticas, estrategias informativas.
Abstract: The Department of Institutional Communication of the European Union (EU) is one of the largest in the world. It produces information on activities of the European Commission, Parliament and the Regional Fund. In recent years, some events (e.g., ones related to the euro, enlargement, constitution, crisis) have tarnished the image of the $E U$ in the eyes of the public. This article examines the intentions and information strategies of large EU communication campaigns at different levels: continental, national and regional. We analyze the direct relationship between the purpose and the result of these communications by examining information produced by the media. The study period is the year 2013, and the sources used are documentation sent by the EU to journalists and news broadcasts of the large Andalusian media. The discussion is about: the distance between the EU and the media; the dehumanized style of EU releases; the lack of correlation between information received from the $E U$ and information issued by the media; the preference for broadcasting news of the EU on economic and infrastructure issues; and that the most common visual identity of the EU is its buildings.

Key Words: European Union, Institutional Communication, Television, Public Relations, Information, news, Andalucia, media campaigns, information strategies 


\section{Introducción}

Desde la antigua Comunidad Económica Europea a la actual Unión Europea (UE), han pasado cinco décadas y la imagen del proyecto ha evolucionado a la vez que se construía políticamente la Unión. Su imagen actual es el resultado de décadas de trabajo pero también de la presión de innumerables mensajes externos que han interferido en la percepción que se han construido los ciudadanos.

Las instituciones europeas son conscientes de la importancia de la comunicación para conseguir una percepción positiva y, de hecho, sus grandes instituciones -la Comisión, el Parlamento y el Consejo- cuentan con los departamentos de comunicación institucional más grandes de Europa. Estos departamentos se han convertido en una gran maquinaria de comunicación institucional, tanto por la capacidad intrínseca que tienen sus líderes, como por las continuas estrategias de relaciones con los medios que ponen a disposición de los periodistas. Esta maquinaria elabora estrategias que podríamos considerar, desde algunos puntos de vista como "intoxicación informativa". Al menos, desde el análisis cuantitativo del emisor de la información, las instituciones europeas generan centenares de comunicados informativos y cuentan con las más modernas tecnologías de la información para difundir su mensaje. Sin embargo, a pesar de esta abrumadora estrategia de comunicación no llegan a construir una imagen sólida que neutralice la actual visión negativa de Europa.

En nuestra investigación intentamos buscar relaciones entre las estrategias informativas definidas por las grandes instituciones europeas, el trabajo de sus departamentos de relaciones con los medios y la producción de información que realiza un medio de comunicación, en este caso Canal Sur Televisión. La observación nos lleva a pensar que el esfuerzo inversor de las instituciones comunitarias no es proporcional al reflejo informativo de gran medio de comunicación, pero será la investigación la que aporte más luz a este posicionamiento inicial. Para analizar esta situación se ha realizado un repaso histórico de las estrategias de comunicación fijadas por la Unión Europea pero también se ha estudiado la difusión de las informaciones institucionales que reciben los periodistas a través del correo electrónico y finalmente se analiza la producción de información que realiza un medio de comunicación, todo ello en un periodo que abarca la totalidad del año 2013. Para realizar la investigación ha sido necesario diversa documentación de las instituciones europeas, conclusiones de jornadas y seminarios a los que han asistido los autores, y el estudio de los correos electrónicos enviados por diferentes servicios de prensa de las instituciones de la UE y que reciben los periodistas suscritos a su lista de distribución. Gracias a la colaboración del servicio de documentación de Canal Sur TV se ha podido realizar un exhaustivo análisis de todas las noticias sobre la UE emitidas por este medio durante un año. Finalmente, también se ha contado con la colaboración del departamento de audiencia del operador televisivo que nos permite aportar datos sobre recepción del mensaje. El análisis de todas estas fuentes nos facilita comprobar los niveles de eficacia que existen entre las estrategias diseñadas por la Unión Europea y la producción de los mensajes informativos que llegan a una determinada audiencia.

\section{Aproximación al marco teórico: La producción de la noti- cia y la Unión Europea}

En ocasiones, resulta complejo establecer el límite entre la información que genera la institución y sus estrategias planificadas de relaciones públicas. Campañas que 
se ven reforzadas por la intensidad comunicativa de las fuentes institucionales de la Unión Europea, máxime cuando combinan, a través de sus numerosas líneas de actuación y diversidad de instituciones, información, relaciones públicas y publicidad. Por tanto, es necesaria una política de información clara, tanto para el ciudadano como para los periodistas. Desde su creación la Unión Europea contó con un departamento de comunicación y relaciones públicas, si bien, su trabajo se intensifica a partir de la década de los setenta por varios motivos, la continua incorporación de países miembros, la creciente pluralidad de medios que demandaban información y la creación de nuevas instituciones como el Parlamento Europeo que necesitaban transmitir a la opinión pública la importancia de una institución representativa con escasas competencias en sus primeros años. Para ello, intervenir en el proceso de producción de la noticia se convierte en algo determinante.

Los medios de comunicación de masas son elementos fundamentales a la hora de acercar la información a los ciudadanos. Como asegura Mac Quail (1983:21) los medios han creado una cultura mediadora en la que tiene un papel protagonista ser el nexo de unión entre un hecho noticiable y la sociedad. Pero para llegar a la sociedad las instituciones deben adaptarse a las pautas que les impone el sistema comunicativo actual, como asegura Ramírez, (1995:35), es lo que conocemos como las rutinas productivas de los medios. Conscientes de esto, la UE intenta aprovecharse de la potencialidad que le ofrecen los medios, especialmente los audiovisuales, puesto que la mayoría de los ciudadanos recurren a ellos como fuente principal de información. De hecho, si observamos los datos del Eurobarómetro, -los estudios de opinión que realiza la Comisión Europea sobre una amplia muestra de todos los países comunitarios y una gran diversidad de temas- en la edición del 2012 al preguntar "Cuando usted busca información sobre la Unión Europea, sus políticas, sus instituciones, ¿qué fuente de información utiliza?", el $50 \%$ en nuestro país reconoce a la televisión como el principal medio, seguido de internet y la prensa. Resulta curioso también comprobar como los ciudadanos consideran (Eurobarómetro 2011) que la información que ofrecen los medios sobre la UE es suficiente y que estas noticias son objetivas, aunque reconocen que no tienen un buen nivel de información sobre la UE. A pesar de ello, la mayoría de los ciudadanos mantiene una percepción negativa de la Unión Europea cuando se les pregunta por la actuación en relación con la situación económica.

Sin duda la televisión sigue siendo el gran medio de comunicación de masas, compartimos con Giovanni Sartori que es la más grande agencia de formación de la opinión pública. Aunque él establece una visión peyorativa por su mala utilización:

"la televisión ha entrado en una carrera competitiva decadente cuyo producto final es, primero, una información reducida; segundo, información improvisada e inútil, y tercero, una desinformación absoluta." (Sartori, 2003:33).

Los medios de comunicación representan un gran poder de información, por su sugerencia o por ofrecer una visión aparentemente real e instantánea (Pérez, 2004:34). Ahora bien, como cuestiona Pérez Rodríguez, habría que saber si estos sistemas de comunicación suponen un mayor nivel de conocimiento y comprensión de la realidad para la población, o sólo para unos pocos. (Pérez, 2004:39).

Consideramos necesario recordar de nuevo a Mac Quail cuando analiza la capacidad de los medios para destacar o silenciar unos acontecimientos u otros y así crear el concepto de opinión pública (Teoría de la Fijación de la Agenda). Como recoge al referirse a los media: 
"por el mero hecho de prestar atención a algunos temas e ignorar otros, tienen un efecto en la opinión pública. La gente tenderá a conocer aquellas cuestiones de las que se ocupan los medios de difusión y adoptará el orden de prioridades que se asigna a los diversos temas". (Mac Quail, 1983:23)

Los grandes medios de masas, en especial la televisión, tienen un código icónico y un lenguaje propio, algo que les lleva a primar los valores de espectacularidad por encima de la reflexión y el análisis. Para Ramonet (1998:19) los informativos confunden emoción con información sin profundizar en las causas, consecuencias o implicaciones que supone ese acontecimiento. Este elemento refuerza su capacidad de persuasión, por tanto, ha sido aceptado por las grandes campañas de comunicación. Las instituciones de la UE son conscientes del valor icónico de la imagen, así como de la necesidad de los medios por disponer de material audiovisual de calidad con un reducido coste de producción. Cumplen así lo que asegura Ramírez sobre que las fuentes deben adaptar sus mensajes a los medios para conseguir presencia informativa.

“...para ganarse la atención de los gatekeeper, los gabinetes de comunicación deben adecuarse a los valores-noticia, estándar que circulan en el mercado: notoriedad del protagonista, adecuación, proximidad del hecho, impacto dramático, interés, novedad, grado de curiosidad, etc." (Ramírez,1995:42)

De esta manera, si los mensajes se adaptan a los procesos de trabajo de los medios será más fácil conseguir esa presencia y por tanto llegar a la opinión pública. Así, todas las instituciones europeas han desarrollado importantes departamentos de comunicación que mantienen estructuras permanentes con relaciones estables con los medios. A diferencia de los grandes departamentos de comunicación institucional de carácter nacional, regional o local, los mensajes de las instituciones comunitarias están menos condicionados por la figura del máximo responsable político. El carácter paneuropeo hace que exista menos personalismo en las estrategias y se piense más en la institución. Los gabinetes de comunicación de la UE han desarrollado amplias políticas de búsqueda de aliados, bien a través de instituciones colaboradoras de tipo administrativo o educativo, o bien, implementando un desarrollo normativo vinculando comunicación con la ejecución de proyectos financiados por la UE.

\section{Estrategias de las grandes instituciones comunitarias para llegar a los ciudadanos}

\subsection{El euro, la gran campaña de comunicación europea}

La comunicación ha sido una prioridad para la Unión Europea, especialmente tras el Tratado de Maastricht de diciembre de 1991, donde se sientan las bases de la Unión Económica y Monetaria, el embrión del futuro euro. Esta gran apuesta implicaba comunicar desde el principio los dos grandes principios de la futura moneda: la gradualidad para acceder a la Unión Monetaria y la posibilidad de hacerlo paulatinamente, lo que se denominó el acceso de "dos velocidades", un término muy usado en Europa para diversos procesos de integración. Entonces, a finales de los noventa, Europa vive unos años de comunicación positiva vinculada a las expectativas de la moneda única, la salida de la crisis de sus miembros, la libertad de fronteras y las elevadas ayudas que llegaban a países perceptores como España.

Las grandes campañas de comunicación sobre el euro comenzaron en 1997 y se fueron intensificando según se aproximaba la fecha de adhesión, hasta llegar a los 
primeros meses de 2002. La campaña presentaba un diseño con características básicas, definiendo la duración, la interactividad, coordinación entre instituciones y seguimiento (Martín, 2003). Las primeras campañas tuvieron un éxito relativo, por lo que fue necesario incrementar en intensidad los mensajes y apoyarse en los niveles regionales y locales para que las acciones fueran más próximas al ciudadano. Las últimas campañas desarrolladas en 2001-2002 se diseñaron con mensajes más directos, como "seis euros mil pesetas". En esta fase fue determinante la colaboración de TVE.

A nivel regional, en Andalucía, la campaña institucional, desarrollada por la Red Euro de la Junta de Andalucía, tuvo una elevada presencia en los medios. La estrategia combinaba numerosas acciones de relaciones con los medios, eventos, acciones educativas o publicidad convencional. Entre ellas es importante destacar la campaña de comunicación "Cuenta con el euro", elaborada sobre microespacios informativos emitidos en los informativos de máxima audiencia de Canal Sur Televisión alcanzando una cobertura del $98 \%$ de la población andaluza. La diversidad e intensidad de esta campaña le llevó a ser reconocida por la Comisión Europea en su informe sobre la preparación de las autoridades locales para la introducción del euro.

\subsection{Los esfuerzos de la Comisión Europea por acercase a los concreto}

La primera década del nuevo milenio la podemos considerar como la más activa de la UE desde sus comienzos. El 1 de enero de 2002 entra en circulación la nueva moneda, en principio para doce países y, poco a poco se fue extendiendo. Lo que en un principio se consideró como el gran logro de unidad europea, rápidamente se asoció a un proceso de encarecimiento de productos del que los ciudadanos culparon al euro. Desde la UE y los gobiernos nacionales fue necesaria una estrategia permanente para neutralizar esa imagen negativa que se extendía entre los ciudadanos.

Para el gran proyecto europeo, la Unión afrontó otros dos grandes retos que no supo explicar adecuadamente. En 2004 se produce la gran ampliación hacia los países del este, pasando de quince miembros a veinticinco, en un proceso cargado de dificultades tanto de organización interna como para justificar la necesidad de esta ampliación. La falta de una comunicación clara provocó que se visualizara a la UE como una institución de difícil gobierno y en algunos estados se responsabilizara a la ampliación de los problemas internos que surgieron tras la llegada de trabajadores de esos lugares, como ocurrió en Francia, donde se creó un símbolo negativo con el titular del "fontanero polaco".

La creación de una nueva Comisión tras las elecciones del 2004, propició que Margot Wallström, nueva Comisaria de Relaciones Institucionales y Estrategia de Comunicación (2004-2009) se planteara la comunicación como elemento clave. Nada más llegar al cargo anunció que entre su acción de gobierno se encontraba fomentar la participación para acercar Europa a los ciudadanos. En este sentido, en abril de 2005 se celebraron en Bruselas las jornadas "Putting Europe in the picture" en las que participaron más de un centenar de periodistas especializados en asuntos europeos que elaboraron una serie de recomendaciones que servirían a la Dirección General de Comunicación para establecer pautas sobre cómo debe ser la comunicación tanto con los periodistas como con los ciudadanos. Mientras tanto, la Unión Europea se esfuerza por alcanzar un acuerdo para consensuar un Tratado de Constitución para Europa, un proyecto de gran envergadura institucional que pasó prácticamente desapercibido en la mayoría de los países. 
La necesidad de ratificación del proyecto de Constitución por cada uno de los países miembros, provocó la gran crisis de comunicación de la década. En nuestro país la campaña del referéndum para la ratificación se articuló bajo el lema genérico de toda la UE, "Una constitución para Europa" y el mensaje específico "Volvemos a Europa". Fue una consulta condicionada por la búsqueda de la fecha más idónea, -finalmente el 20 de febrero de 2005- marcada por las tensiones del cambio del gobierno del PP al PSOE. Concientes de la imagen negativa que se estaba fraguando en nuestro país hacia la UE tras la implantación del euro, nos encontramos con una campaña breve pero intensa, cargada de gestos populistas en la que no faltaron actores, músicos o humoristas apostando por la ratificación del proyecto constitucional.

Si bien, el punto de inflexión en la actual política de comunicación de la UE la marca el rechazo francés y holandés al referéndum de la Constitución Europea. A partir de ese momento, el Consejo Europeo de junio de 2005 abre lo que denominó como "periodo de reflexión para movilizar a los ciudadanos", una propuesta que se articulaba bajo la denominación de "Plan D". Según explicitaba en sus objetivos: "La Comisión ha propuesto un Plan D para la Democracia, Diálogo y el Debate, no como una operación de rescate para la Constitución, sino para estimular un amplio debate entre los ciudadanos y las instituciones democráticas de la Unión Europea" (2005). En la propuesta que la Comisión envía al Consejo se recoge una serie de acciones que afectan a las instituciones, los ciudadanos y los medios de comunicación. El plan llega recomendar a los países miembros que utilicen el remanente que tenían destinado a las campañas del referéndum constitucional, ya suspendido, para los nuevos objetivos de comunicación.

La presentación del Plan D, unido al informe del Parlamento sobre "Estrategias de Comunicación e información, conocido como Informe Herrero (2004) sentaron las bases del "Libro Blanco sobre una política europea de comunicación". Este documento reconoce que la información sobre la UE es mejorable "la cobertura de los asuntos europeos por los medios de comunicación sigue siendo limitada y fragmentaria." (2006:9). El documento establece tres objetivos claros sobre los que hay que trabajar:

- Humanizar a Europa. La Unión Europea es percibida a menudo como "anónima", buscar el "interés humano".

- Dimensión nacional, regional y local. Los ciudadanos europeos tienen que acceder a un flujo constante de información común.

- Explotar el potencial de las nuevas tecnologías. Las tecnologías digitales, como Internet.

A estos tres objetivos hay que añadirle la reiterada recomendación de comunicar hacia los jóvenes. Todas las recomendaciones del Libro Blanco son claves para entender las estrategias informativas seguidas por las grandes instituciones europeas desde el año 2006 hasta ahora.

El periodo de la eurocomisaria Wallström fue uno de los más intensos en materia comunicativa, llegando a recibir diversas críticas por el exceso de información. Acusaciones que aclaraba la eurocomisaria en una entrevista al grupo de presión Institución Futuro, (2009:02) "La palabra propaganda tiene una gran carga peyorativa y la emplean con demasiada frecuencia los euroescépticos. Quienes nos critican deberían saber que los ciudadanos reciben información a través de varios medios independientes: la Unión no controla los medios ni los temarios educativos a nivel nacional. Cuando se nos acusa de propaganda, en realidad se están refiriendo a ac- 
ciones para promover la participación, lo que intrínsecamente va en contra de la propaganda -que no busca el debate, sino la aceptación pasiva de ciertos principios".

Algunos de esos grupos contrarios al exceso de información de la Unión Europea han criticado la altas inversiones dedicadas a estas acciones pues sobrepasaban en 2007 los 213 millones de euros anuales según el conocido como informe Timbro (2009:4), aunque Wallström aseguraba que no superaba los cien millones. Sin embargo, la crisis económica ha convertido a la Unión Europea en el objeto de fuertes críticas lo que ha propiciado un aumento del euroescepticismo en algunos países, y provocando que los grandes medios de comunicación reduzcan la presencia de corresponsales en Bruselas, algo anunciado, en 2010, por el Vicepresidente de la Comisión Europea Antonio Tajani en un encuentro en España con responsables de medios de comunicación.

El Parlamento Europeo, al igual que la Comisión, asume las recomendaciones del Libro Blanco pero es especialmente significativo el esfuerzo de la Convención, encargada de elaborar el proyecto de Constitución para Europa, por acercar las instituciones a los ciudadanos, como asegura Del Río

"es durante la Convención, encargada de escribir la Constitución, cuando la participación de los movimientos y organizaciones de la sociedad civil tiene una mayor visibilidad, repercusión y escucha. Con la Convención europea, la participación consigue otra dimensión." (Del Río, 2009:3)

La participación es la gran preocupación del Parlamento Europeo y para fomentarla desde 2009 sus campañas adquieren una nueva dimensión. A partir de ese año y bajo el lema "Tu eliges", el Parlamento diseña, por primera vez, una gran campaña para todos los países miembros. Con esta estrategia la institución consigue dos grandes objetivos, unificar los criterios de comunicación y reducir gastos. La campaña estuvo basada en las recomendaciones del Libro Blanco e intenta acercar las consecuencias de las decisiones del Parlamento con mensajes muy directos sobre consumo, telefonía o derechos humanos. Así, tanto la Comisión como el Parlamento han diseñado una amplia estrategia de recursos para medios de comunicación apoyada en las nuevas tecnologías. Entre ellas conviene destacar:

- Gran desarrollo de portales en Internet

- Amplios recursos gratuitos para los periodistas: servicios de cámaras, platós de TV, estudios de radio, conexiones satélites para realizaciones de directos, set para programas, etc.

- Banco de imágenes gratuito, el más grande del mundo

- Uso de satélites para distribución de imágenes

- Amplio desarrollo de distribución de Europe by Satellite, pasando a dos frecuencias en simultaneo. EBS, EBS+.

- Utilización de Youtube como una recurso más de la Institución

- Recursos de videos virales en momentos puntuales. Especialmente interesante la estrategia viral puesta en marcha por el Parlamento Europeo para fomentar el voto en las elecciones del 2009 


\section{4. ¿Cómo informar de las grandes inversiones del fondo regional?}

Para llegar al ciudadano, la mejor comunicación es la que se produce en los ámbitos de proximidad. Precisamente, ésta era una de las recomendaciones del Libro Blanco de la Comunicación (2006:12), "centrar los logros de la Unión Europea en el terreno local”. Así una de las grandes políticas de la UE, ha sido la política regional. Con sus inversiones se pretende combatir las diferencias entre las regiones europeas, pues no podemos olvidar que una de cada cuatro tenía un PIB inferior al $75 \%$ de la media -el criterio de asignación de fondos se ha utilizado hasta el año 2012-, y en este grupo se encontraba Andalucía.

Desde la incorporación de España en la Unión Europea, Andalucía ha recibido miles de millones de euros a través de diversas líneas de inversión (FEDER, FSE, FEADER, Fondo de Cohesión) que abarcan todo tipo de ejecuciones: infraestructuras, creación de empresas, formación laboral, asistencia social, etc. Una importante cantidad de dinero que ha servido para igualarse con otras zonas de Europa, como aseguraba Valverde, de forma global se recibieron en la comunidad autónoma hasta 2006 más de 54.000 millones de euros, a los que habrá que sumar los más de 25.000 millones de euros que están asignados para el periodo 2007-2013. Las inversiones del Fondo Regional se han ejecutado por periodos de seis años, en lo que se conocen como Programas Operativos, para autores como Benedicto (2006:9), se podría considerar como la mayor operación de solidaridad de la historia. Y es que los fondos regionales son uno de los elementos más visibles de la integración de España en la Unión Europea, como aseguran, Piedrafita, Steinberg, y Torreblanca (2007).

Las primeras obligaciones sobre la comunicación de las inversiones comunitarias las encontramos en la década de los 90. La Unión Europea ya recomendaba a los estados beneficiados de estos fondos la importancia de identificarlos de forma visual. Sin embargo, esta obligatoriedad no iba más allá de lo que conocemos como la identidad visual corporativa, la identificación de la bandera europea y el nombre del fondo de donde procedía la inversión, y apenas existía un trabajo de supervisión. Fue a principios del 2000 cuando la UE emitió una comunicación al Consejo y al Parlamento sobre la estrategia de información y comunicación para la Unión Europea donde (Guía aplicación: 2000) se recoge la importante cuota de responsabilidad de los estados miembros en la difusión de la información, especialmente sobre las disposiciones relativas a los Fondos Estructurales de la UE, dictando normas de obligado cumplimiento para los gestores de estos fondos.

Esta obligatoriedad por transmitir unos objetivos de comunicación se articula en diversos reglamentos que abarcan casi todas las líneas de trabajo: a nivel general actividades relacionadas con la información y publicidad (CE1159/2000), y otra específica para el fondo de Cohesión (CE 621/2004)

Desde el año 2000 se han desarrollado dos periodos operativos de inversiones del Fondo regional en el que todas sus actuaciones han tenido un seguimiento estrecho para que se visualizara la identificación con Europa.

En este sentido, destaca la importancia que le concede el Fondo Regional al diseño de planes de comunicación, desde el mismo momento en que se presentan las propuestas para recibir fondos europeos. Así, es importante destacar el plan de comunicación de la Dirección General de Fondos Europeos de la Junta de Andalucía para el periodo 2007/13 que se ha venido ejecutando en los últimos años. Si bien es cierto, que la relación que mantiene esta Dirección General directamente con los medios es 
limitada al no contar con un departamento de comunicación, con lo que su eficacia se basa en la información que generan sus proyectos y los trabajos desarrollados por la agencia de publicidad que ejecuta las acciones del plan de comunicación.

\section{Análisis de la información de la Unión Europea en los pro- gramas informativos de Canal Sur TV}

Para comprobar si existe relación directa entre el gran esfuerzo inversor en comunicación institucional y la información aparecida en los medios, nos hemos centrado en el principal medio de comunicación de masas, la televisión. Como ámbito de análisis lo acotamos a Andalucía, en concreto a su televisión autonómica Canal Sur TV. Hemos elegido este medio porque presta una gran atención a la información europea, debido a la repercusión directa en Andalucía de algunas políticas comunitarias (agrícola o fondos sociales y regionales), y además, porque durante el año 2013, Canal Sur TV era de las pocas televisiones en España con un programa dedicado a la actividad de las instituciones europeas y disponía de una corresponsalía en Bruselas.

Conscientes de la importancia que tiene el proceso de producción de la noticia así como la relación entre la fuente informativa y el medio de comunicación, hemos considerado importante realizar un estudio cuantitativo de la información que recibe un periodista suscrito a las listas de correo de las principales instituciones comunitarias. Para ello, ha sido necesaria la colaboración de un profesional perteneciente a la plantilla del medio analizado. Con él hemos contabilizado la recepción de los mensajes de tres de las principales fuentes informativas de la UE: la Comisión, el Parlamento Europeo y la Dirección General de Fondos Europeos de la Junta de Andalucía.

Desde el Gabinete de Comunicación de la Comisión Europea en Madrid se distribuyen diariamente todas las informaciones que genera la Comisión en Bruselas, más los actos específicos que se producen en España. Por la dimensión de la institución observamos que es el gran motor informativo de la Unión. Solamente en el año 2013, un informador suscrito a su servicio de correo electrónico recibió 676 mensajes informativos. El servicio homólogo del Parlamento Europeo en nuestro país presentó una cantidad menor, con 72 informaciones, si bien las comunicaciones de la Eurocámara fueron más selectivas destacando las principales medidas aprobadas en las sesiones de Estrasburgo, así como una gran cantidad de eventos locales celebrados en el país. Finalmente, al centrarnos en el terreno regional, observamos que los envíos desde la administración autonómica con contenido europeo descienden considerablemente y tan solo se recibieron una decena de mensajes, fundamentalmente centrados en la conmemoración de actos con motivo del Día de Europa o la difusión de algunos proyectos financiados con fondos comunitarios. Observamos como existe una relación directa entre cantidad de información y existencia de gabinetes de comunicación especializados.

Andalucía es la región más poblada y la segunda más extensa de España. El índice de audiencia de Canal Sur TV está en torno al $10 \%$ de share y sus informativos suman un tercio de su programación total. Por ello, consideramos importante realizar un estudio cuantitativo de las noticias emitidas, pero profundizando en el elemento de análisis de contenido de cada una de ellas para poder agruparlas por categorías temáticas. Normalmente, los programas informativos de Canal Sur TV se agrupan en "diarios" y "no diarios", según un doble criterio de periodicidad y de contenido. Es decir, no sólo depende de su frecuencia de emisión, también de si es estrictamente de actualidad general. Por ejemplo, "Andalucía Directo", se emite diariamente de 
lunes a viernes, pero se ha analizado como "no diario" pues su formato no se centra directamente en la actualidad. La búsqueda se realizó para todo el año 2013, tanto en los "informativos diarios" como, los programas informativos de carácter semanal, conocidos como "no diarios". Como programas "diarios" estarían seis espacios de noticias: "Primera Hora", "Buenos Días Andalucía", "Noticias 1", "Noticias 2", "Telenoticias" y "La Noche al Día". En el caso de los "no diarios" los hay más informativos y otros más divulgativos. Existen culturales, medioambientales, religiosos, o de perfiles especializados. En total son 15 los programas incluidos en esta categoría, aunque sólo en 3 de ellos se produjo alguna referencia.

Basándonos en una serie de palabras clave y bajo los criterios usados por el Servicio de Archivo, Documentación y Biblioteca ${ }^{1}$ de Canal Sur TV, para las búsquedas del material emitido, se han introducido los siguientes descriptores:

1 La consulta se ha podido hacer contando con la colaboración de miembros del Servicio. La solicitud de búsquedas desde fuera de Canal Sur -algo que no es corriente-, hay que tramitarlas a través de la Jefa del Servicio, y depende de la complejidad y de la disponibilidad de personal el poder llevarlas a cabo.

1. Banco Central Europeo

2. Banco Europeo de Inversiones

3. Comisión Europea

4. Comité de las Regiones

5. Comité Económico y Social

6. ECOFIN

7. Consejo de la Unión Europea

8. Consejo Europeo

9. Constitución Europea

10. Defensor del Pueblo Europeo

11. Euroescepticismo

12. Eurogrupo

13. Eurozona

14. Instituciones de la UE
15. Inversiones comunitarias

16. Legislación comunitaria

17. Organizaciones internacionales

18. Órganos consultivos europeos

19. Órganos financieros europeos

20. Parlamento europeo

21. Política económica de la UE

22. Presidencia de la Unión Europea

23. Presupuestos de la UE

24. Procesos de adhesión a la UE

25. Rescate económico

26. Tribunal de Cuentas Europeo

27. Tribunal de Justicia de las comunidades europeas

28. Unión Europea 
En total han aparecido 197 documentos con alguna referencia europea, entendiendo por documento aquella información audiovisual emitida que ha sido analizada y registrada por los documentalistas de Canal Sur. Hay que tener en cuenta que alguno de estos documentos no respondía al objetivo de la búsqueda aunque contenía palabras claves, y por tanto se ha descartado, o se había contabilizado dos veces por registrarse por separado la declaración y el vídeo de la noticia, aunque el contenido se refería a la misma información. Tras esa revisión han quedado 158 documentos válidos. Hemos respetado la separación entre "no diarios" y "diarios" al analizar los datos puesto que en el primero la referencia está vinculada necesariamente a la actualidad, mientras que en el segundo caso, hay una mayor casuística.

\subsection{En los informativos "diarios"}

Son 120 las referencias localizadas en los archivos de Canal Sur (en un año pueden estimarse en unas 30.000 las noticias emitidas). Tras analizarlos, hemos fijado un criterio de agrupación con diez categorías generales: crisis económica relacionada con las medidas en España, protestas contra la política de la UE, Fondos Europeos y Política Agraria Común, relacionadas con Andalucía, cumbres europeas, rescate económico, Parlamento Europeo, Comisión o Consejo, política exterior y otros.

Hay que señalar que algunos temas podrían entrar en varias categorías, optamos por incluirlos en la que se ciñe mejor al enunciado. Por ejemplo, el rescate a Chipre se considera "rescates" y no "cumbres" o "consejos".

A continuación se detallan las categorías analizadas:

- 1. Crisis relacionada con España: La mayoría de estas noticias aparecen en la primera mitad de año. Son, entre otras, una reunión del ministro de Economía con el comisario correspondiente en la que hablan de desempleo, una previsión sobre incumplimiento de déficit, dos sobre posible flexibilización de los criterios del déficit, una inspección de la troika para analizar la situación española, los préstamos de Alemania a pymes españolas, y una sentencia del Tribunal de Justicia de la UE sobre desahucios.

- 2. Protestas: Dada la impopularidad de las medidas pensábamos que aparecerían más registros sobre descontento, y sólo en dos ocasiones se informa de manifestaciones, una en Portugal y otra en Chipre, aunque a veces, se incluían relacionadas con otros contenidos.

- 3. Política Agraria Común y Fondo Regional: Importante para Andalucía porque se negociaba un nuevo reparto en la política agraria común (PAC). A pesar de la importancia de este tema para Andalucía el número de noticias es relativamente bajo y son principalmente del proceso de negociación de la PAC.

- 4. Andalucía: Aquí nos encontramos con informaciones generadas en las instituciones europeas con repercusión para Andalucía, o las noticias generadas en Andalucía sobre la UE. Así, hay unas jornadas europeas en el Parlamento de Andalucía, una visita de la Consejera de Presidencia a las instituciones comunitarias, un estudio sobre la repercusión del nuevo presupuesto comunitario, una sentencia que reduce los fondos FEDER a la región, la aprobación del plan hidrológico del Guadalquivir cumpliendo una directiva del agua, y la discusión de la acción del gobierno central ante la Comisión por la ley de vivienda andaluza.

- 5. Cumbres europeas: las reuniones de los jefes de gobierno de la UE reclaman una gran atención de los medios, aparecen 16 registros, especialmente en el primer semestre, debido a las intervenciones económicas Otros temas son los 
relacionados con los presupuestos comunitarios para los próximos siete años, combatir el fraude fiscal, o medidas contra el paro juvenil.

- 6. Rescates: Tras los rescates a Irlanda, Portugal y Grecia, se produjo el de Chipre, que llamó la atención en 23 ocasiones, mientras que otras 5 fueron referencias a un estudio que recriminaba fallos en el rescate hecho a Grecia.

- 7. Parlamento Europeo: Se agrupan noticias de actividad de la cámara, como la aprobación de una norma reguladora de las agencias de calificación, el tratamiento de los desahucios en la comisión de peticiones, dos noticias sobre la inclusión de la dación en pago en legislaciones de cada país, una sobre el cierre de la televisión pública griega, la comparecencia de un comisario para hablar de desempleo, una iniciativa para eliminar los céntimos y un previo a una reunión. En el segundo semestre son llamativas las noticias del premio Sajarov a la joven Malala, y el debate de los presupuestos de la UE.

- 8. Comisión y consejos: El gran generador de información de la UE es la

- Comisión y, especialmente, las reuniones de los consejos europeos. Hubo 25 noticias del ECOFIN (Consejo de Ministros de Economía y Finanzas) vinculadas a las medidas contra la crisis, en las que el principal actor político fue el ministro español, Luís de Guindos. El resto de las informaciones se dedica a reuniones de Ministros de Empleo o de Interior, donde se abordan desde la reforma de las pensiones, crédito a las pymes, lucha contra el déficit o instalación de medidas de seguridad en las fronteras de Ceuta y Melilla

- 9. Política exterior de la UE: En esta categoría aparecen claramente tres conceptos en la segunda mitad del año, el conflicto diplomático entre España y Reino Unido por problemas en la frontera de Gibraltar, la necesidad de reforzar las fronteras de la UE por la llegada de inmigrantes y el conflicto de Ucrania.

- 10. Otros: Se recogen temas diversos, como la prohibición de pesticidas que matan abejas, el acoso a un europarlamentario en Escocia, alguna sobre el Banco Central Europeo y el mantenimiento de los tipos de interés o el recuerdo por la muerte de Nelson Mandela.

Cuadro 1. LA UNIÓN EUROPEA EN INFORMATIVOS CANAL SUR TV

\begin{tabular}{|c|c|}
\hline \multicolumn{2}{|c|}{ LA UNIÓN EUROPEA EN INFORMATIVOS CANAL SUR TV - 2013 } \\
\hline CATEGORÍAS & NOTICIAS EMITIDAS \\
\hline CRISIS MEDIDAS ESPAÑA & 2 \\
\hline PROTESTAS CONTRA UE & 2 \\
\hline PAC+FONDOS & 11 \\
\hline ANDALUCÍA & 16 \\
\hline CUMBRES EUROPEAS & 28 \\
\hline RESCATE ECONOMICO & 19 \\
\hline PARLAMENTO & 36 \\
\hline COMISIÓN + CONSEJOS & 17 \\
\hline POLÍTICA EXTERIOR & 5 \\
\hline OTROS & 2 \\
\hline
\end{tabular}


La distribución de las noticias fue la siguiente: 65 veces en "Noticias 1", 64 en "Noticias 2", 17 en "La Noche al Día”, y 12 en "Buenos Días". De ellas, 62 veces fueron en forma de colas (locución del presentador sobre imágenes), y el resto, 96, en un vídeo elaborado. 43 noticias fueron realizadas por la corresponsalía en Bruselas, y casi todas ellas relacionadas con la celebración de cumbres o consejos, incluyendo cinco entradas en directo en el informativo.

\subsection{En los informativos "no diarios"}

Se han contabilizado 38 contenidos europeos en los programas "no diarios", veinte de ellos son de "Europa Abierta", ocho "Parlamento de Andalucía", uno "Tierra y Mar" y otro "Andalucía Directo".

"Europa Abierta" al ser un espacio específico para esta información, repite alguno de los temas que se han tratado en diarios, como la crisis de Chipre, la situación de la banca española, el combate al fraude fiscal, la desaparición de las monedas de céntimo, la dación en pago estudiada por el Parlamento Europeo o la intervención en Mali; sin olvidar otros que son de actualidad, pero que no fueron incluidos en los diarios como la respuesta comunitaria a la guerra en Siria, la repercusión del referéndum de independencia de Escocia, la negociación de un tratado de libre comercio con Estados Unidos, el ingreso de Croacia en la UE, los desequilibrios de la economía española, el cambio de estrategia económica en la UE o la visita de los inspectores de la troika para analizar el decreto andaluz de la vivienda. Además, incluye otros de mayor sentido europeísta como la celebración en 2013 del año europeo de los ciudadanos, la unificación de los documentos de identidad en todos los países, una campaña de denuncia del problema de la violencia de género, la situación del matrimonio homosexual en Europa, o un informe sobre las enfermedades infecciosas. En todos los programas se incluye un vídeo elaborado por la corresponsalía en la capital europea acerca de actualidad comunitaria.

En cuanto "Parlamento Andaluz", donde se refleja la actividad en la cámara autonómica, se recogieron tres informaciones sobre las jornadas europeas celebradas en su sede, dos sobre reuniones de parlamentarios de asambleas regionales, una del recorte de fondos europeos para Andalucía, otra de cómo afecta el presupuesto europeo, y una más de la visita de la troika europea para estudiar la ley de la función social de la vivienda.

"Tierra y Mar" trató las enmiendas a la Política Agraria Común y su negociación, y "Andalucía Directo", al hablar de un desahucio en Almería, recordó el anuncio del gobierno de adaptar la normativa europea y la sentencia del Tribunal de Justicia Europeo.

AUDIENCIA INFORMATIVOS. CANAL SUR TV. 2013

Cuadro 2. AUDIENCIA INFORMATIVOS. CANAL SUR TV.

\begin{tabular}{|c|c|c|}
\hline PROGRAMA & ESPECTADORES & CUOTA AUDIENCIA \\
\hline Buenos Días & 42.000 & $9,0 \%$ \\
\hline Noticias 1 & 339.000 & $16,4 \%$ \\
\hline Noticias 2 & 238.000 & $10,3 \%$ \\
\hline La Noche al Día & 38.000 & $12,3 \%$ \\
\hline Andalucia Directo & 247.000 & $13,1 \%$ \\
\hline Tierra y Mar & 235.000 & $3,5 \%$ \\
\hline Europa Abierta & 15.000 & $6,5 \%$ \\
\hline Parlamento Andaluz & 72.000 & \\
\hline
\end{tabular}

Fuente Kantar Media y elaboración propia 


\section{Conclusiones}

La investigación parte de una revisión de las fuentes relativas a las estrategias de comunicación que ha desarrollado la Unión Europea en los últimos años. La UE ha implementado toda una estrategia tendente a conseguir mayor difusión de las políticas comunitarias. Sin embargo, como ya advertía Del Río al analizar criterios de participación ciudadana y la UE, "llama la atención que la nueva oleada participativa todavía no tenga un reflejo en el interés de la sociedad por los temas europeos, incluso se podría hablar de cierta asimetría entre el espacio más participativo y el que tiene que ver con la comunicación entre los ciudadanos y las instituciones europeas." Para la Unión Europea los medios de Comunicación son un pilar fundamental para transmitir los logros de la UE a sus audiencias, como recogía el "Libro Blanco de la Comunicación", elaborado por la Comisión Europea. Sin embargo, deberíamos preguntarnos si existe una relación directa entre inversión en comunicación institucional o relaciones públicas y noticias aparecidas en un medio de comunicación, y por tanto informaciones recibidas por los ciudadano.

El trabajo de campo del estudio toma como muestra de análisis los correos enviados a los medios tanto por los departamentos de comunicación de la Comisión y del Parlamento y analizando la cobertura informativa realizada sobre el objeto de estudio por Canal sur TV. Se pueden observar algunas conclusiones claras aplicadas al año 2013. Desde el punto de vista institucional, el año 2013 fue de una gran intensidad para la UE debido a varios factores. El primero de ellos, la crisis económica, que obligó a la Comisión Europea a tomar medidas con respecto a Chipre o Grecia. Pero además, ese periodo coincidía con el fin de una legislatura en el Parlamento Europeo y con el final del periodo de inversión 2007-2013 del Fondo Regional. Todos estas factores generan una mayor actividad legislativa e institucional en la UE, según destaca en su informe general del 2013 en su informe general sobre la actividad de la Unión Europea (2014: 26).

A la hora de contrastar las estrategias de comunicación diseñadas por las grandes instituciones recogidas en el Libro Blanco de la Comunicación y los envíos de información a los periodistas, observamos que el objetivo de proximidad de los mensajes queda prácticamente diluido por las grandes decisiones de la Comisión Europea, prácticamente la totalidad de los mensajes tienen su origen informativo en Bruselas o Estrasburgo y el plano de Andalucía es casi inexistente. Además, al analizar estos envíos de información encontramos una relación directa entre la existencia de grandes gabinetes de comunicación y la producción informativa. Se puede comprobar la desproporción existente entre los mensajes enviados por el departamento de la Comisión Europea y los emitidos por los responsables de asuntos europeos de las instituciones andaluzas. Esto se debe a que en Andalucía, a pesar de tener un completo plan de comunicación de fondos europeos no existe un Gabinete de Comunicación específico para esta materia.

La investigación que se ha realizad evidencia que el 2013 estuvo marcado por grandes acontecimientos económicos y, por tanto, el mensaje que se transmite a los es la identificación de UE con la economía, todo lo contrario a las recomendaciones de humanización del mensaje informativo recogidas en el Libro Blanco de la Comisión Europea. El campo economía impregna los descriptores de "crisis", "Consejo" o "Comisión. Sin embargo, prácticamente la totalidad de estas noticias tienen una elevada relevancia informativa y están elaboradas por la periodista corresponsal. No se observan que formen parte de campañas de comunicación institucional. Es importante comprobar como estas noticias de carácter económico, -caso Chipre- a pesar 
de contar realidad no profundizan en las causas de las medidas o en la repercusión de sus consecuencias, lo que podría humanizar el discurso de la UE. Los análisis de fondo sobre la ciudadanía de esos países se abordan poco y sólo en forma de protestas.

Existe una relación directa entre la presencia de una periodista corresponsal en Bruselas y el número de coberturas informativas emitidas, si bien la inmensa mayoría son de asuntos económicos. Igualmente, la existencia en Canal Sur de un programa especializado en asuntos de la UE genera noticias para los informativos de la cadena. En estas dos acciones tienen una relación muy directa las estrategias de comunicación de la UE, en el caso de la corresponsal facilitando el trabajo, conexiones y un banco de imágenes gratuito; y en el programa específico favoreciendo todo tipo de materiales audiovisuales y en ocasiones manteniendo acuerdos de cofinanciación sobre ciertas informaciones.

Al analizar la temática de los correos emitidos por las grandes insitituciones y las noticias emitidas por el medio de comunicación, observamos que no existe una relación directa entre producción y emisión. Las instituciones generan una gran cantidad de información institucional de la que sólo llega a la emisión alrededor de una décima parte de los mensajes producidos. Podríamos hablar de una infoxicación informativa por parte del gabinete de la Comisión Europea. En el extremo opuesto encontramos la producción de información del Fondo Regional en Andalucía, donde las noticias aparecidas en este apartado son prácticamente inexistentes, siendo mucho mayores las noticias referidas a otros sectores como los estudiantes Erasmus. Hay que tener en cuanta que el Fondo Regional desarrolla estrategias de comunicación específicas para Andalucía, aunque la mayor parte de su inversión tiene un carácter muy publicitario que se escapa a este estudio.

Por tanto, podemos concluir que no existe una relación clara entre la estrategia inversora en comunicación institucional de la UE y las noticias aparecidas. La actualidad sigue marcando la agenda informativa del periodista, lejos de los objetivos de comunicación planificados por las instituciones comunitarias. El principal recursos comunitario que utilizan los periodistas en sus noticias son las imágenes de las instituciones de los servicios audiovisuales tanto de la Comisión como del Parlamento Europeo, que aparecen en más de un sesenta por ciento de los casos. En lo que refiere a la temática de las informaciones la mayoría se refieren a conceptos económicos lo que puede provocar gran distanciamiento de la opinión pública. Resulta muy significativo comprobar como otras temáticas muy próximas al ciudadano como las inversiones en obras, infraestructuras o las ayudas a la agricultura son prácticamente inexistentes por lo que se pierde la oportunidad de transmitir información positiva en el terreno de lo local.

\section{Referencias bibliográficas}

\subsection{Libros}

BENEDICTO, MIGUEL ANGEL y GONZALES, JOSÉ L. (2006) La mayor operación de solidaridad de la historia. Crónica de la política regional de la EU en España. Madrid. Plaza y Valdés.

CASTILLO ESPARCIA, ANTONIO (2009). Relaciones Públicas. Teoría e historia. BarceIona: UOC. 
COLOMBO, FURIO (1976). Televisión: La realidad como espectáculo. Barcelona: Gustavo Gili.

MCQUAIL, DENIS (1983). Introducción a la teoría de la comunicación de masas. Barcelona: Paidós.

MAC QUAIL, D. y WINDDAHL, S. (1984). Modelos para el estudio de la comunicación colectiva. Pamplona, EUNSA.

MARTÍN SEGOVIA, EDUARDO (2003) La campaña del euro (1996 2002): la unión monetaria europea como objeto de comunicación política y opinión pública. Tesis Doctoral. Madrid. Universidad Complutense

PÉREZ RODRÍGUEZ, Ma . AMOR (2004). Los nuevos lenguajes de la comunicación. Enseñar y aprender en los medios. Barcelona: Paidós.

RAMÍREZ, TXEMA (1995). Gabinetes de Comunicación. Funciones, Disfunciones e incidencias. Barcelona: Bosch.

RAMONET, IGNACIO (1998): La Tiranía de la Comunicación. Madrid: Debate.

RODRIGO ALSINA, MIGUEL (1989). La construcción de la noticia. Barcelona. Paidós.

SARTORI, G. (2003). Videopolítica, Medios, información y democracia de sondeo. Madrid: Fondo de Cultura Económica.

THOMASSON-LERULF, PHILIP (2009). Informe TIMBRO, "The European Union's burden". Timbro. Brussell.

VAVERDE RAMOS (2006). La huella de Europa en Andalucía. Servicio de Estudio y Publicaciones, Consejería Economía y Hacienda. Junta de Andalucía. Sevilla

\subsection{Artículos en revistas}

DEL RIO, SUSANA (2009). Comunicar, clave para aumentar la participación en las elecciones europeas de 2009: de un modelo europeo de debate a una política comunicativa europea Área: Europa - Real Instituto Elcano, ARI No 88

INSTITUCIÓN FUTURO (2009). ¿Comunicación efectiva en la Unión Europea? Tendencias de futuro newsletter del think tank. Institución Futuro. Huarte.

PIEDRAFITA, S.; STEINBERG, F. TORREBLANCA, J.I. (2007). La europeización de España. Real Instituto Elcano de Estudios Internacionales y Estratégicos. № 39. DOI: $10.2307 / 20646098$

\subsection{Otros recursos}

COMISIÓN EUROPEA (2000). Comunicación de la Comisión al Consejo, al Parlamento europeo, al Comité económico y social y al Comité de las regiones sobre la estrategia de comunicación en las últimas fases de realización de la UEM Bruselas, 2.2.2000 COM (2000) 57 - final.

COMISIÓN EUROPEA (2005). The Commission to the Council, the European parliament, the European economic and social committee and the committee of the regions The Commission's contribution to the period of reflection and beyond: Plan-D for Democracy, Dialogue and Debate. European Commission. Brussels.

COMISIÓN EUROPEA (2006). Libro Blanco sobre una política europea de comunicación. Comisión Europea. Bruselas, 
DIRECCIÓN GENERAL DE COMUNICACIÓN (2013). Informe General sobre la actividad de la Unión Europea 2013, Bruselas. DOI: 10.2775/85595

DIRECCIÓN GENERAL DE COMUNICACIÓN. Cómo funciona la Unión Europea. Bruselas. DOI: $10.2775 / 20072$

JUNTA DE ANDALUCÍA (2000). Manual de información y Publicidad de Fondos Europeos en las actuaciones cofinanciadas en la Junta de Andalucía. Dirección General de Fondos Europeos.

PARLAMENTO DE ANDALUCÍA BOPA Número 131, Serie A VI Legislatura Año 2001, Comisión de Economía, Hacienda y Presupuestos. Sevilla

RESÚMENES DE CONCLUSIONES, jornadas para medios de comunicación, "Putting Europe in the picture", 2005, Bruselas.

7.4.- Referencias web

EUROBARÓMETRO, Standard 76, otoño 2012

http://ec.europa.eu/spain/sobre-la-ue/euro-barometro/index_es.htm

EUROBARÓMETRO, Standard 76, otoño 2011

http://ec.europa.eu/spain/sobre-la-ue/euro-barometro/index_es.htm 
